\title{
The Ethics of Blockchain in Organizations
}

\author{
Monica M. Sharif ${ }^{1}\left[\right.$ [ $\cdot$ Farshad Ghodoosi $^{2}$
}

Received: 1 October 2020 / Accepted: 25 January 2022 / Published online: 2 February 2022

(c) The Author(s), under exclusive licence to Springer Nature B.V. 2022

\begin{abstract}
Blockchain is an open digital ledger technology that has the capability of significantly altering the way that people operations (i.e. human resource management) operate in organizations. This research takes a first step in proposing several ways in which the blockchain technology can be used to improve current organizational practices, while also considering the ethical implications. Specifically, the paper examines the role that blockchain technology plays in three primary areas of people operations: (1) entry to the organization (via recruitment and selection), (2) intraorganizational processes (including compensation via smart contracts, retention and motivation via shared leadership and conflict management via network-based dispute resolution, and performance management), and (3) exit (offboarding). In each section, the paper reviews the ethical implications from the lenses of virtue ethics, utilitarianism, deontology and contractarianism. The paper concludes that in whole the implementation of blockchain technology in people operations processes can create a more ethical work environment. However, careful implementation is necessary and requires extensive examination of ethical implications in advance.
\end{abstract}

Keywords Blockchain · Artificial Intelligence $\cdot$ Ethics $\cdot$ People operations $\cdot$ Human resources

\section{Introduction}

Organizations are constantly evolving. The gig economy (Frenken et al., 2020), frequent job switching (Allen et al., 2010), new communication methods (Gajendran \& Joshi, 2012), globalization of labor force (Tsui et al., 2007), and technological advancement (Orlikowski, 2000) are among the factors that have contributed to the dynamic change of organizations in recent years. Most notably, the technological disruption, which the Covid-19 pandemic significantly accelerated, has brought "years of change" in organizational

The authors would like to thank The Fintech Center at Morgan State University for their support of the original research idea presented in this paper on blockchain and organizations.

Monica M. Sharif

msharif@calstatela.edu

Farshad Ghodoosi

farshad.ghodoosi@csun.edu

1 Department of Management, College of Business and Economics, California State University, Los Angeles, 5151 State University Drive, Los Angeles, CA 90032, USA

2 Department of Business Law, David Nazarian College of Business and Economics, California State University, Northridge, 18111 Nordhoff St., Northridge, CA 91330, USA behavior (Mckinsey \& Company, 2020). The speed of organizational change emanating from emerging technologies is undeniable.

Blockchain is one of these emerging technologies. Despite its importance, little do we know about blockchain's potential for organizations-specifically people operations ${ }^{1}$ - and the associated ethical ramifications. As with most new change, there is great potential for positive advancement in organizations, however there are also ethical dilemmas that need to be considered. In this paper, we address both of these challenges. We coin the term decentralized people operations (DePo), for blockchain's application on people operations, and offer a systemic ethical analysis of DePo for organizations. Specifically, this paper explores the role that blockchain can play in people operations starting from recruiting and selecting

1 The terms "people operations" and "human resource management" will be used interchangeably throughout this paper. Human resources management is more commonly used in the academic literature, whereas people operations has become a staple term in industry, especially in large technological companies including Google, Apple and Facebook. In industry, there has been a pivot in the approach to understanding and working with employees. Whereas human resource management typically views employees as resources that need to be managed, people operations views employees as individual contributors that can provide competitive advantage for the organization (Farrar, 2019). For the purposes of this paper, we will use both terms alike to speak to both audiences: academia and industry. 
employees, compensation, retention and motivation to performance management. Each section investigates the ethical implications of blockchain from virtue ethics, utilitarian, deontology, and contractarian viewpoints.

Blockchain is a decentralized form of verifiable digital record-keeping (Iansiti \& Lakhani, 2017). Blockchain offers much potential for people operations in organizations. We categorize blockchain's capabilities in people operations into (i) entry to organization, (ii) intraorganizational affairs, and (iii) exit from the organizations. At the entry stage, blockchain can change the recruitment and selection process. In intraorganizational processes, it can revamp compensation through smart contracts, retention and motivation through shared leadership and conflict management through a network-based dispute resolution to name a few. At the exit stage and offboarding, blockchain can provide opportunities for organizations to engage in more transparent and efficient processes.

Blockchain's ethical issues for organizations stem from its three main promises: immutability, disintermediation (distributed verification), and automation. Immutability results in the permanency of a human past record and raises ethical issues such as privacy and transparency concerns (Hofmann et al., 2017). Disintermediation refers to horizontal decision-making and the numerosity of stakeholders in verifying outcomes (Quiniou, 2019). Disintermediation raises ethical issues related to accountability and equal opportunity. Automation refers to the self-executing features of coded agreements called smart contracts (Szabo, 1996) which raises issues related to human dignity among others.

This paper is among the first to map out DePo at various phases of people operations. First, this paper brings light to privacy challenges for the entry and exit stages of people operations while arguing that contractarianism-based on a hypothetical ex ante contract-can best capture the associated ethical issues. As for intraorganizational affairs, the paper offers fresh views of blockchain's potential impacts on compensation, shared leadership, conflict management, and performance evaluation. It suggests that each of the applications requires separate ethical analysis. For instance, on shared leadership and a new form of conflict managementwhat we call distributed conflict management (DCM) - virtue ethics with its focus on human flourishing best captures the associated ethical nuances. From a broader perspective, this paper contributes to the existing literature by showing how emerging technologies can foster the transition from the purely utilitarian view of human resources to a more collaborative environment. In achieving so, the paper analyzes the ethical ramifications of emerging technologies which requires in-depth understanding of their disruptive potentials and a more robust stage-by-stage analysis that is not merely related to the consequences of emerging technologies.

\section{Theoretical Background}

\section{A New Kid on the Block}

Blockchain technology is a new form of trust and choice architecture, which allows for the disintermediation of third parties (Werbach, 2018). At the heart of blockchain technology is a new form of "consensus" that makes it possible for the platform and users to make decisions without oversight and presence of a third party. For example, if person $\mathrm{A}$ is transferring a sum of money from her account to person $\mathrm{B}$, banks record the transaction. In blockchain and crypto-economics, other users of the platform record the transaction. By multiplying the ledgers that include the transaction, blockchain makes it extremely difficult for a single user or even a group of users to manipulate the transaction or double-deal. The blockchain platform often includes an incentive mechanism to encourage users to participate in the record-keeping process. Most notably, in the Bitcoin platform, the users are rewarded if they solve complex mathematical problems (called mining) (Böhme et al., 2015). In essence, blockchain is a crowd-based or peer-to-peer platform, which enables verification and storing of information with the help of all of its users (i.e., disintermediation). The information is stored in digital blocks, which creates a chain of immutable information (Tapscott \& Tapscott, 2017).

Blockchain enables a new network-based decision-making process whereby users are not merely the recipients of information of decisions but also the decision-makers (Ghodoosi, 2021). Put differently, at its core, blockchain enables the creation of value through a consensus-based verification mechanism based on an incentive structure. Values, therefore, are created not by trust in a government (e.g., dollar) but based on verification of others (Tapscott \& Tapscott, 2017). Moreover, in blockchain platforms, users are often anonymous or pseudonymous which enables a new form of engagement with the network and a new type of decision-making (Aitzhan \& Svetinovic, 2016). Even though the technology is still in a nascent phase relative to other technologies, blockchain's promise lies in its new form of rendering organizational decisions that can change the structure of organizations.

\section{The Power of Artificial Intelligence and Blockchain}

The relationship between blockchain and AI is evolving. Blockchain is a record mechanism enabling distributed decision-making and immutable record keeping. However, the information that is fed into the blockchain system and ultimately printed into the blocks in a blockchain 
can be AI-enabled. In other words, $\mathrm{AI}$ is the connection between blocks and the external data. For example, imagine a blockchain-based distributed ledger social network. All users' public information is stored on blocks. However, new blocks can be added based on AI algorithms which collect the information of users (e.g., about their preference for a presidential candidate) and store them into new blocks. One difference between the distributed social network and the existing one is that AI algorithms allow for further decentralization (elimination of central planning) as the $\mathrm{AI}$ algorithms determine the information that is shared among users and added to new blocks. One can further imagine that both the AI algorithm and the types of information recorded can be modified pursuant to the consensus mechanisms (similar to a constitution) adopted as the underlying basic logic of this social network. The use of blockchain jointly with AI in organizations presents novel ethical questions given that the immutable data storage capability of blockchain meets the ever-increasing capability of AI in generating data.

\section{Organizations Dipping Their Toes}

Blockchain technology has begun to be implemented in a variety of business processes at several organizations. Most notably, the blockchain technology has made an important impact on the finance industry through the use of cryptocurrency (Truong et al., 2018). Blockchain's use is also on the rise in production and supply chain management. For instance, following the wide-spread contamination of romaine lettuce, Walmart launched a test pilot of blockchain for its supply chain to be able to find the source of its goods faster and more efficiently (Corkery $\&$ Popper, 2018). In addition to Walmart, as many as fifty large organizations, such as Amazon, JPMorgan and BP have taken steps in adopting blockchain technology in some forms (del Castillo, 2019). Blockchain technology also lies at the core of several hundred start-ups which are using the technology in insurance (e.g. encoding rules for damages reimbursement), governmental institutions (e.g. identity management by automating identity checks), healthcare (e.g. automating processes such as prior authorization for specific treatments), and the sharing economy (e.g. creating peer-to peer autonomous organizations replicating services such as Airbnb and Uber). Overall, aside from the startup scene, up until now blockchain has been primarily used in finance and supply chain logistics. Few organizations have taken steps to integrate blockchain technology into their human resources practices (BasuMallick, 2020).

\section{The Incomplete Ethics Picture}

Quite recently, an interest in the ethics of blockchain has developed in the literature. The existing literature however has not focused on the impacts of blockchain on organizational ethics. These articles often provide recommendations for future research which include discussion of ethics in management and human resources.

In a review of the ethics of blockchain, Tang et al. (2020) discuss the ethics of blockchain's technology stack by examining privacy, accuracy, property and accessibility. They also discuss the ethics of cryptocurrencies, smart contracts and decentralization for institutions, society and governance. Their analysis did not focus on any particular ethical theories, but rather a general review of the ethics of different levels of blockchain. Tang et al. (2020) also express the important need for more in-depth research into specific areas of business including in areas of management. In another article, Hyrynsalmi et al. (2020) conducted a systematic literature review of blockchain and ethics and found that current research is lacking with regard to discussion of the consequences of blockchain. Particularly, the authors found an absence of specific ethical theories in discussions of blockchain and therefore recommended that future research draw on particular ethical frameworks. The authors also suggest that future work focus on the application of blockchain technology to different practical contexts.

Other than review articles, other research on blockchain and ethics has discussed the risks associated with full acceptance of trust in blockchain over trust in others (He, 2020) and the potential of "hardcoding ethics" by creating decentralized autonomous organizations (DAOs) that encode all operating rules, thereby limiting human discretion (Sulkowski, 2020). Dierksmeier and Seele (2020) provide a business ethics perspective to blockchain technology and its different applications. Specifically, they examine favorable, unfavorable and ambivalent dimensions of blockchain technology utilizing four theories of ethics (utilitarianism, contractarianism, deontology and virtue ethics). The authors highlight the need for thorough analysis of the ethics of blockchain considering that there may be many advantages yet at the same time disadvantages that arise from blockchain. Advantages include unprecedented degrees of transparency and accuracy in addition to cost reduction and efficiency of process. Disadvantages may include loss of jobs that consist of routine tasks which may lead to an increase in income inequality. Blockchain-based cryptocurrencies may also enable money laundering in addition to other illegal transactions. In their analysis of ethically ambivalent applications of blockchain, Dierksmeier and Seele (2020) discuss the ethics of the move from institutional trust to transparency, algorithms in job platforms and privacy that is limited to most but transparent to only a few. 
These discussions bring forth important ethical issues in the field of business as a whole and call for further research on other aspects of blockchain in business that have ethical implications. Addressing these calls for research, we examine ethical perspectives for the implementation of blockchain in people operations.

\section{Decentralized People Operations (DePo)}

Blockchain technology has caused some to question whether there is a real need for formal organizations and pushed many to reflect on the underlying trust assumptions of organizations (Seidel, 2018). However, other scholars have argued that online peer-to-peer communities, such as those outside of a formal organization, cannot run solely by protocols and algorithms but require a form of social institution to establish accountability and safeguard the legitimacy of the system as a whole (De Filippi, 2015; De Filippi \& Loveluck, 2016). Although discussion about the need for formal organizations as whole exists in the literature, the majority of research on blockchain in business has focused on applying blockchain to improve certain aspects of organizational performance. Specifically, blockchain has been mainly applied in finance (cryptocurrencies) and supply chain (Akter et al., 2020; Chang \& Chen, 2020; Felin \& Lakhani, 2018; Treleaven et al., 2017). In finance, blockchain has unleashed a new nascent industry often referred to as decentralized finance ( $\mathrm{DeFi}$ ) which is growing at a rapid pace (Sandner, 2021).

However, blockchain and its underlying mechanism has the ability to transform other areas. Most notably, blockchain has the potential to disrupt people operations. This is where blockchain can have a vast impact on human interactions and human decision-making in organizations. From recruitment and selection to performance management, organizations can utilize blockchain technology to streamline their employee management processes, making it all the more efficient providing benefits to both the employees and the organization itself.

We will call this area DePo. DePo is where the human experience in organizations will be most affected by blockchain and AI. DePo has the potential to create new forms of choice architecture for all stakeholders in organizations including leaders and employees.

Stone et al. (2015) in a review of literature at the intersection of technology and human resources found that this area is very nascent with many avenues for future research. The authors specifically called for additional research to examine the extent to which the implementation of technology in human resource practices enables organizations to achieve their human resource goals. Existing reviews of blockchain and ethics have not thoroughly discussed the role that blockchain can play for human resources and organizational behavior (Tang et al., 2020). The existing literature primarily has looked at the features of blockchain and its applications in different sectors (i.e. Kher et al., 2020). There are handful of reviews related to the intersection of blockchain and management. However, in the majority of these reviews (i.e. Alkhudary et al., 2020; Frizzo-Barker et al., 2020; Kher et al., 2020; Kimani et al., 2020; Klarin, 2020; $\mathrm{Xu}$ et al., 2019), human resource management was not even mentioned. The literature on blockchain in human resource management is nascent. Only a handful of scholars have started to investigate it from a management perspective. For example, Fachrunnisa and Hussain (2020) discussed the creation of a human resources training supply chain in which skills needed in the industry are found via blockchain algorithms. In the field of engineering, scholars have begun to develop protocols and platforms that will allow blockchain functionality in organizational recruitment processes (Öncu, 2019) and work history fraud prevention (Sarda et al., 2018). Equally, discussion of ethics in blockchain is nascent (Tang et al., 2020) and does not engage discussions related to human resource management.

\section{The Ethics of DePo}

As blockchain makes its way into organizational decisionmaking, it is imperative to have a better understanding of the ethical issues. Literature on the ethics of human resources has questioned the basic principle of viewing people as simply "resources" of an organization (Greenwood, 2002). As explained in this paper, with new forms of choice architecture, blockchain has the potential to create new forms of organizational decision-making for leaders and employees. Individuals' careers, prosperity, motivation, and overall happiness will be affected by these new forms of organizational decision-making. These changes will not only have micro impacts. These new forms of decision-making can ultimately lead to DAO. DAO aims to create organizations based on distributed decision-making (Wang et al, 2019) whereby the lines between leaders and employees become murky. DAO promises a true stakeholder model which can have macro impacts on the ways organizations are formed and organized. It is therefore imperative to understand the impacts of blockchain on people operations to have a better grasp of ethical issues.

Similar to DeFi, DePo relies on disintermediation, immutability, smart contracts, and network verification processes. Disintermediation refers to elimination or reduction of verifiers in each transaction or decisions (Quiniou, 2019). Immutability refers to the blockchain ability to record information without allowing an entry point for manipulation of the data (Casino et al., 2019). Smart contracts refer to coded (computable) agreements which make the enforcement selfexecuting (Ghodoosi, 2021). The network-based verification 


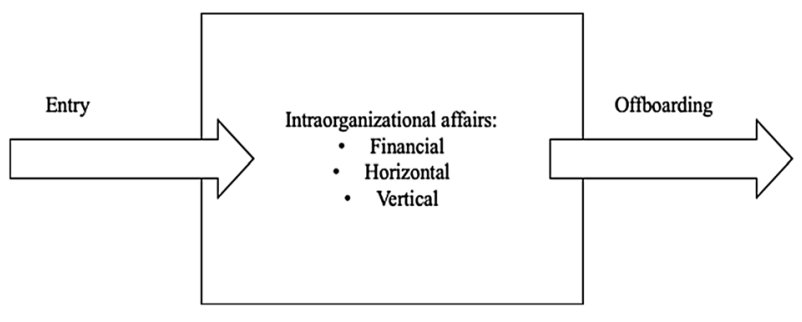

Fig. 1 Categorized aspects of people operations

process refers to users' ability to validate the information pursuant to pre-defined consensus mechanisms prior to inclusion of such information on the next block (Natarajan et al., 2017). These key features can have lasting impacts on different aspects of people operations.

Generally speaking, we categorize various aspects of people operations into three: entry, intraorganizational affairs, and offboarding as shown by Fig. 1.

Based on these three stages, in the following sections, we have chosen five primary areas of people operations-1. Recruitment and selection, 2. Compensation, 3. Motivation and retention, 4. Performance management, 5. Offboarding - to discuss the ways in which blockchain can be applied. The goal is not to discuss all aspects of people operations, but rather to briefly review the primary categories and detail some of the important areas in which blockchain can have a consequential impact. Additionally, using the model from Dierksmeier and Seele's (2020) paper, within each section we review the ethical implications from four viewpointsvirtue ethics, utilitarianism, deontology, and contractarianism-for each of the human resources practices discussed. Below we will first briefly review the ethical theories that we will be relying upon in the sections below.

\section{Ethical Theories}

Normative ethical judgement depends in part on the adopted ethical approach. We have adopted a framework based on the components of an act along with its apriori status. Generally, acts can be viewed from three perspectives: the agent who engages in the act, the act itself, and the consequences of the act. Ethical theories have placed the emphasis on each of these elements. Additionally, another perspective approaches the ethical issue from an ex-ante perspective (prior to the act) pursuant to a hypothetical behind-the-veil social agreement. Even though the lines between the ethical theories become murky at times (Koehn, 1995), this framework enables a structured ethical analysis that we will use for the purposes of this paper.

Traditionally, ethics dealt with transcendental values that were inherently virtuous independent of the associated outcome or agents who acted in accordance with such values.
This approach is the doctrine that emphasizes moral virtues. Virtue ethics approaches an act in relation to certain virtues. In the business setting, the virtue ethics approach includes a long list of virtues recognized in the business setting. This includes values such as fairness, justice, honor, reliability, respect, responsibility, integrity, trust, trustworthiness, wisdom among others (see e.g., Brewer, 1997; Brinsfield, 1998; Dean, 1992; Card, 2010; Gier, 2001; Limbs \& Fort, 2000; McCracken et al., 1998; Murphy, 1999; Seeger \& Ulmer, 2001; Solomon, 1992; Shanahan \& Hyman, 2003; Tessman, 2000).

We find the emphasis on human capabilities as a helpful approach in virtue ethics especially in the context of the present discussion (Bertland, 2009). Pursuant to this view, and for the purposes of this paper, an institution or a technological advancement is ethically judged based on its ability to flourish humans and elevate human dignity (Nussbaum, 2000). Accordingly, actions are ethical if the character trait of the act leads to human flourishing (Annas, 2004; Foot, 2003).

Another approach is Utilitarianism which unlike virtue ethics bases the ethical evaluation on the consequences of an act. This approach is a teleological view based on ultimate rewards and punishments and submits that acts are just if they benefit the majority (Hansen, 1992; Hunt \& VasquezParraga, 1993; Louden, 1992). Utilitarians emphasize that the greatest happiness for the greatest number of people should be the guiding principle. In sum, utilitarians examine both the good and the bad consequences arising from an action.

Contrary to utilitarianism which looks at the consequences of an action to determine its morality, Deontology is an agent-based norm-keeping ethical approach. Deontology states that individuals are morally obligated to act according to a particular set of principles and rules irrespective of the outcome. Deontologists believe that certain absolute principles such as honesty should be obeyed regardless of the outcome (Brady \& Dunn, 1995; Cody \& Lynn, 1992). Actions are deemed right or wrong based on a series of rules and agents' duties (Micewski \& Troy, 2007). One of the negative duties arising from a deontological perspective is the obligation to do no harm (Scheffler, 2002) which can be helpful in the context of the present discussion.

Another ethical approach frames the ethics of actions a priori and behind a veil of ignorance. Contractarianism (Rawls) is the approach that examines ethicality regardless of one's status in society. Pursuant to this approach, society is in a form of agreement with all those who are in the society (Dunfee \& Donaldson, 1995). Rawls has proposed two primary principles: principle of equal liberty and principle of equality (Rawls, 1991). The first principle indicates that all citizens have an equal right to basic liberties. The second principle suggests that economic principles should meet two 


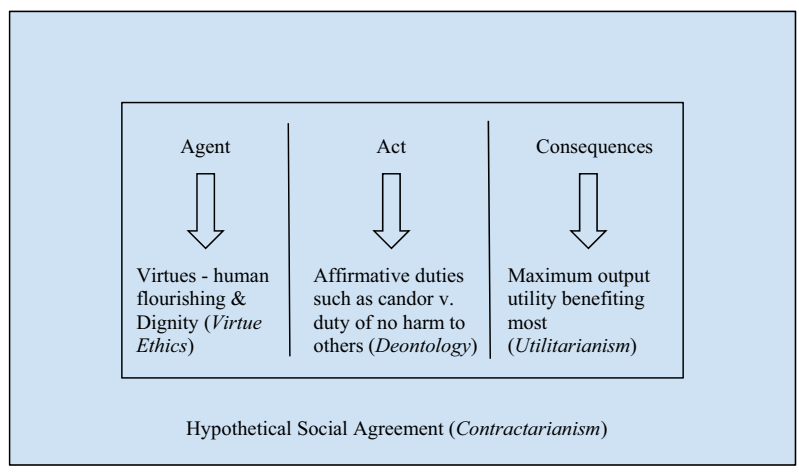

Fig. 2 Ethical framework to analyze blockchain in people operations

requirements. The first requirement is that the least advantaged in society should receive a greater number of benefits. The second requirement is that all individuals should have equal chance and equality of opportunities.

Based on the foregoing, we propose the ethical framework in Fig. 2 to analyze the issues related to blockchain in people operations.

\section{Conceptual Framework}

In the following sections, we will review the primary areas in which blockchain can influence people operations, as well as their ethical implications.

\section{Entry-Recruitment and Selection}

The first step in building strong organizational relationships is recruiting and selecting strong employees that fit with the team and organizational culture. Selection of top-notch employees makes it easier to retain and motivate, train and develop and manage employee performance. Leaders and organizations benefit from employees who develop longlasting relationships with the organization (Meyer \& Allen, 1991) partially because they save on turnover costs (both time and money), which again includes recruiting, selecting, retaining and motivating. In the gig economy, it is now very common for employees to frequently change their employment. In most organizations, employee turnover has steadily increased over the years and is now much higher than it used to be in the past (Work Institute, 2019). Organizations therefore spend a significant amount of time reviewing resumes, verifying degrees and previous work experience, conducting background checks, and so forth. For these reasons, it is important to have an effective system that makes the recruitment and selection process as streamlined as possible. Blockchain technology can assist with this.

Blockchain technology provides organizations with a straightforward way to verify potential employees and their backgrounds (Tapscott \& Tapscott, 2017). Making the application process transparent (Angel \& McCabe, 2015; Meyer \& Hudon, 2019), blocks of information about potential employee recruits can be easily verified. Therefore, the use of blockchain in the recruitment and selection process provides a check of the applicants. For example, applicants may include false information on their resumes. They may include names of references that are not appropriate sources to judge their previous performance. Instead of listing a previous supervisor, they may list a friend from their previous company instead. They may also report higher performance evaluations than they actually achieved. When blockchain is used, all of the applicant's information is permanently recorded on different sets of blocks. Those items recorded on a "block" have been verified by stakeholders with knowledge of that individual in the voting process. For example, if an applicant submitted a performance evaluation from a previous company, this performance evaluation would be verified by those who have knowledge of the applicant's performance at that company. This, in effect, prevents applicants from overstatements or underreporting. Dierksmeier and Seele (2020) discussed at length the role that blockchain plays in assuring trustworthy information in the hiring and assessment processes of organizations. Therefore, blockchain offer us tools to verify the truth.

Changes to this information are nearly impossible to make, therefore, making the information immutable and trustworthy (Casey \& Vigna, 2018). Hence, when making hiring decisions, leaders can be confident in the backgrounds of their recruits because of information verified via blockchain. Assuming that blockchain can always record accurate information, it will result in unprecedented transparency in the recruitment process. A growing body of literature emphasizes and empirically shows the value of 'transparency signaling' in stakeholders' perception of organizations (Carroll \& Einwiller, 2014; Rawlins, 2008; Rim et al., 2019). This level of transparency once achieved by blockchain can create a higher level of trust in organizational decision-making. On the other hand, however, individuals' privacy will equally be affected. Increasingly, individuals' "right to be forgotten" is being recognized as a counterbalance to the intrusive effects of technology (see e.g. EU General Data Protection Regulation Article 17 on right to erasure or right to be forgotten). Blockchain's immutability feature presents a new challenge for privacy especially in areas in which individuals' background plays a critical role such as in recruitment and selection. 


\section{The Ethics of Using Blockchain in Recruitment and Selection}

As stated above, virtue ethics includes a long list of desirable virtues. In this paper, we view virtue ethics from the capability lens and focus on human dignity (Nussbaum, 2011). If the use of blockchain in recruitment and selection results in actualizing human potential and flourishing, a virtue ethicist would find it ethical. Having a verified and transparent recruitment and selection process has long been a hurdle for applicants and people operations departments. Streamlining and verifying credentials and past performance can help a greater number of applicants have better access to flourish in the organization and realize their capabilities. It is therefore possible to conclude that virtue ethicists would favor the use of blockchain technology in the recruitment and selection process because the intention of the use of blockchain technology in itself is to provide a fair playing field to all applicants. The ethical road is perhaps bumpier if one adopts a utilitarian or deontology perspective as explained below.

Utilitarians would examine the consequences of using blockchain technology in the recruitment and selection process. One primary consequence would be that the organizations would have accurate information by which to evaluate candidates. Since blockchain would provide verification of the information and documents that candidates are submitting with their applications, the applications could be considered very trustworthy. This would make the playing field fair for all applicants. Without blockchain technology, the possibility for inclusion of fraudulent information in the application process is greater. Another consequence, however, would be that blockchain technology reduces privacy. If employees do not have control over the background information provided to employers, they may feel the violation of privacy. For example, if a previous employer wrote a negative evaluation of an employee, this might be permanently recorded on one's file, which may have long-term consequences on that specific employee's job prospects. That negative evaluation could have been written by a previous employer who had a grudge against the employee for some reason. In sum, a utilitarian would look at the "use" of the blockchain technology for a greater number of people. Given that transparency in hiring can affect a greater number of people, it can be concluded that pursuant to this approach, blockchain-driven transparency outweighs privacy concerns. Relatedly, the way blockchain is implemented is important. For example, perhaps applicants may have discretion over which pieces of verifiable information could be shared with the organization. This would give candidates the choice of which pieces of information to share, while still providing verifiable data to the organization.

Deontologists may find the implementation of blockchain technology in the recruitment and selection process complex. From one lens, they would favor the use of blockchain technology in the recruitment and selection process because the rules would be consistent for all applicants. Blockchain helps the duty of candor in the entry phase. All applicants would be subject to submitting the same documentation and same procedures, all of which would be verifiable. On the other hand, the use of blockchain may cause harm to certain groups of people, especially those who aspire to change course in their lives. Put differently, the applicants' duty of candor is weighted against organizational practice of no harm particularly on those who do not want to be tied to their verified past. Deontologists may wrestle with this dilemma. Perhaps the greater good of transparency and equity in the application process would outweigh the possible harms.

A utilitarian or a deontologist most likely has to engage in balancing between the different ethical concerns as explained above. A contractarian, however, may form a different ethical scheme given that the emphasis is on social agreement. Contractarians would look at the hypothetical social contract concluded between job-seeking candidates and organizations who are engaged in recruitment and selection. This hypothetical agreement (behind the veil of ignorance or without knowing one's status) would most likely emphasize fairness, transparency, and having an equal opportunity. Contractarians would like to see equal rights in the recruitment and selection process. Therefore, they would deem the process ethical if all applicants were subject to the same recruitment process. Since blockchain technology would make the process equitable for all of those who are applying to different positions, contractarians would consider this ethical. Additionally, the least fortunate should at the very least be given the same consideration as other applicants. Blockchain technology should level the playing field by providing all individuals with the opportunity to submit their applications without fraudulent activity.

\section{Intraorganizational-Compensation}

\section{Smart Contracts}

After choosing the best employees for the team, contracts need to be signed to set the rules and expectations of the employment relationship, especially as it relates to compensation and benefits. A critical part of a blockchain platform is its smart contracts. Smart contracts are encoded agreements that make contracts self-executing and certain decision-making processes automated (Ghodoosi, 2021). Smart contracts consist of if/then algorithms, which define the rules of the game from the start. Often, such rules cannot be modified and are immutable. A pioneer in blockchain technology and the person who coined the term smart contracts illustrated it by providing the example of transacting with a vending machine (Szabo, 1996). Another example pertains 
to Bitcoin. The rules determining who receives Bitcoin lies at the core of this platform and can hardly be changed. Most famously, platforms such as Ethereum enable users to deploy smart contracts to automate all or part of contracting. For example, a user can deploy a smart contract whereby a digital asset will automatically be transferred to a user who has placed the highest bid in a digital auction (Chen et al., 2018). This automation makes the "breach" of a contract extremely difficult, if not impossible.

Smart contracts can also be used in disbursing employee compensation. Smart contracts can automatically release funds once employees meet certain pre-defined conditions. The use of pre-defined conditions will lessen the possibility of delay or denial of compensation after employees have met those conditions. The immutability along with the self-executing feature of smart contracts enable a more expeditious and less arbitrary compensation scheme. Blockchain helps to restore the customer-first orientation of competitive markets by removing the reliance on traditional intermediaries such as banks (Dierksmeier \& Seele, 2020). Moreover, conditions have to be clearly defined ex ante for a smart contract to be able to function (e.g., if an agent's sales volume meets a certain threshold, that agent is entitled to the pre-defined exact amount of bonus). The clear pre-determination of conditions will enhance objectivity and lessen discrimination and ex-post arbitrary denials. The challenges with smart contracts include lack of entry points and incompleteness of the computer codes (Ghodoosi, 2021). Put differently, the immutability of smart contracts may result in undesired outcomes (lack of accountability) in unpredicted scenarios (i.e., scenarios that were not accounted for in the computer codes). This can be resolved by an effective ex post dispute resolution mechanism as discussed in the shared leadership section further below.

\section{The Ethics of Blockchain in Compensation and Benefits}

A virtue ethicist would likely find smart contracting challenging. On the one hand, smart contract features bring about accountability, transparency, and speed to transactions while minimizing the chance of breach. The ex-ante predefined conditions help employees and individuals involved in such transactions. Consequently, employees can focus on fulfilling their career potentials while reducing the chances of disputes. On the other hand, smart contracting reduces the possibility of bargaining and negotiation (Ghodoosi, 2021). Some find the very act of negotiation moral as it creates a relationship between promisor and promisee (Markovits, 2004) and helps foster relational justice (Ackerman, 1997). The automation of obligations can therefore negatively affect human dignity as points of entry to negotiations and bargaining minimize.
Focusing on the consequences of smart contracts provide a different ethical perspective. The consequences of using smart contracts for the enactment of compensation include providing more efficiency for organizations and employees. With streamlined payments, employees will be appropriately paid upon completion of a task. When work is completed, employees will be automatically paid. Since the breach of contract would be difficult, employees can feel secure that they will get properly paid for their work. Moreover, smart contracting incentivizes participants to include objective pre-determined criteria (codes) as the terms of the agreement are immutable. This way transparency and accountability are promoted. The existence of the possibility of incompleteness in computer codes will also incentivize users to pre-define their relationship with more accuracy and use an effective dispute resolution mechanism afterwards.

Smart contracts formalize and automate the duty to perform. Deontologists would likely favor smart contracts because the rules are defined before the start of any employment contract. This helps minimize the possibility of breach and increases the possibility that parties abide by their duty to perform their promissory obligations. It is likely that smart contracts result in certain harms to individuals especially if the pre-defined terms are one-sided. However, this presents no different ethical issue than the boilerplate agreements of today (Radin, 2012). Moreover, since the terms of smart contract need to be clearly defined for it to be selfexecuting, the chances that ambiguous terms are used will be reduced. Additionally, the possibility of shared leadership by blockchain as explained below provides more bargaining power to employees to include more equitable terms in smart contracts.

Contractarians would look for equality in the distribution of compensation. Employees would be treated equally in that they would all be subject to smart contracts to receive their compensation. The least fortunate would receive payment in the same manner as other employees. Every employee would have automatic issuance of payment. The employees, for example, could be given options by the organization for payment issuance, whether that be a mailed check or a direct deposit, etc. Once the method is chosen, the smart contracts would issue the payments upon completion of the work.

\section{Retention and Motivation via Justice and Shared Leadership}

After the organization completes an excellent recruitment effort, they want to make all efforts to motivate and retain those hires. It is important for organizations to create an environment in which employees want to stay because the costs of turnover are so great for an organization. Retention and motivation aim to create a horizontal relationship between leaders and employees to create a thriving working 
environment. One of the primary ways in which organizations can retain employees is by enacting fairness (Aquino et al., 1997; Colquitt et al., 2001). Justice and transparency are essential.

One way to motivate and retain employees is by giving them a voice in organizational processes (Rees et al., 2013; Spencer, 1986). Due to the decentralized nature of blockchain, it has the potential to change the dynamics of organizations. Similar to the structure of many technologyfocused organizations, the span of control is reduced and blockchain organizations have a more boundaryless structure (Ashkenas, 1995; Devanna \& Tichy, 1990). Organizations relying on blockchain may encourage shared leadership in which leadership responsibilities are more distributed among employees in the organization (Pearce \& Conger, 2002; Pearce et al., 2008). This process of shared leadership can be seen in the consensus mechanisms on which blockchain is founded. For example, the consensus mechanism can be designed such that any assignment submitted by an employee can be voted on by any other employee in the system as defined. Employees have open access to a significant amount of data including the proposed blocks. All users in blockchain have the ability to vote for or against any block that is attempting to be added to the blockchain. Therefore, blockchain allows for a distributed and equal voting process to occur in which employees can voice their opinions. This allows for true distributed shared leadership. Moreover, this process saves significant amounts of time for leaders dealing with competing demands for their time. Actions that they choose can be distributed to other employees on the team. At the same time, the decision-making process may result in some delays since decisions that are made horizontally involve a large group of stakeholders. However, the idea of blockchain and its underlying game theory is to incentivize users to participate (e.g., by providing tokens) expeditiously and widely in the decision-making process.

Another way that organizations can use blockchain to instill this sense of justice is using distributed conflict resolution (DCM) at work. Organizations can utilize smart contracts to encode the possibilities that lie in a decision tree. Employees can then resolve conflicts by acting as jurors by selecting an outcome which will then be enforced (Ghodoosi, 2021). Whether it is called distributed justice (Metzger, 2018), crowd arbitration (Gudkov, 2020), or mob justice (Schmitz \& Rule, 2019), this new potential can lead to a new form of trust between individuals within organizations. Not only can certain decision-making processes in an organization be automated but they can be achieved (verified) by others within the organization (Chen et al., 2018). For example, imagine a complaint by an employee about his or her working condition. Traditionally, it is expected of the leaders to fairly resolve the issue in silo without involving others in the organization. In a blockchain and smart contract model, the employee's grievance however can be resolved by a network of leaders and members alike who can submit proposals and vote on the issue. Organizational responses would then be recorded in the grievance process (White, 2017). The consensus mechanism allows for a resolution to form a transparent block in the decision-making process of the organization. The decision forms a precedent for which all participants are aware. This model can be most helpful in big organizations where decision-making processes are often opaque and would not constitute precedent. The notion of the leader therefore changes to someone who can incentivize such participation.

\section{The Ethics of Blockchain in Retention and Motivation}

Providing voice to employees is key for their dignity and flourishing. Engaging employees both in decision-making and in conflict management provides a new type of work experience. Virtue ethicists welcome such a development as employees find new ways to participate and flourish in the workplace. Employee opportunities to voice their opinions and engage in shared leadership provides them with a sense of dignity and avenues for growth in the organization.

Utilitarians would also favor the use of blockchain in retention and motivation. Particularly, shared leadership would be significantly enhanced with blockchain technology. Shared leadership would occur in the organization in which decisions could be made via a collective voting system pursuant to a defined consensus mechanism. This would increase employees' participation and voice in routine organizational processes. Therefore, a sense of justice and morality would be created. Another consequence is that employees would all be subject to the same conflict resolution processes via blockchain technology. This would give employees the sense that there is a procedurally just system in place for issues that arise at work. The problem of perceptions of justice is a sticking point in alternative dispute resolution (Ghodoosi \& Sharif, 2021). A DCM based on blockchain technology can alleviate concerns related to justice perceptions in alternative dispute resolution. In this fashion, the organization would also be viewed as one that desires to provide equitable treatment to its employees.

Deontologists would likely find both the possibility of shared leadership and distributed justice appealing. Organizations have a duty to respect and transparency. Both shared leadership and distributed justice enable organizations to fulfill these duties. The use of blockchain can however result in harm to certain groups of employees. This may happen if employees have similar backgrounds or a particular way of thinking which leads them to judge an 'outlier' in the organization. In this scenario, the collective action may lead to collusion and therefore can cause harm to minorities. It is therefore imperative to have in place mechanisms to detect 
any collusion, bias or discriminatory practices. AI can help in finding such patterns (Pierson et al., 2018).

Contractarians would likely find shared leadership and distributed conflict management ethical. In this fashion, employees would be treated equally in that they would all have the opportunity to engage in shared leadership. Additionally, they would all have the opportunity to engage in the same conflict resolution process. This provides a necessary standard because a network of individuals would partake in resolving the issue allowing for multiple points of view to be expressed. If we were to design a system behind a veil of ignorance, we would most likely design a system where most employees can participate in leadership and conflict management. The least fortunate would also have the opportunity to voice their opinions and be subject to the same conflict resolution process. Therefore, they might be given more opportunities to voice their opinions than they would have normally received in an organization that does not employ blockchain technology.

\section{Performance Management}

Effective management of employee performance can also be affected by blockchain technology in many ways including verifying work history prior to employment, reciprocal verification of assignments and performance evaluations.

\section{Verifying Authenticity Prior to Employment}

Blockchain allows information to be verified. Therefore, before adding an individual to a team, organizations can verify necessary employee information. This can include prior performance evaluations at previous companies, history of task completion, and variety of skills based on previous assignment completion among others. Just as listed in the recruitment section above, blockchain provides an opportunity for organizations to access this reliable data before making personnel decisions. This is very important to leaders deciding who they want to have on their team. It also provides a good background for all those that will be working with the specific employee.

\section{Verifying Assignments}

In leader-member relationships, both dyadic partners go through a process of evaluating the other member and making initial judgments. A reciprocal pattern occurs in which assignments are given by the leader and the follower responds by completing the assignments. After a series of exchanges, the relationship moves from one stage to another. It starts with the role taking phase in which the exchanges are very transactional in nature, and then moves on to the role making and role routinization phases in which high quality leader-member relationships are typically found (Graen \& Scandura, 1987).

Blockchain adds an additional layer of this checks and balances process by providing checkpoints and verification at every step of the process. For example, with blockchain, leaders can specify the details of every assignment and include it on a block. The follower then has access to that clear information and is tasked to complete it. When the follower completes the assignment, it is again recorded on a block. The leader then evaluates the assignment and again records the evaluation on a block. Especially in the role taking phase, which is a very essential time for leaders and followers to develop quality communication (Graen \& Scandura, 1987), blockchain can provide transparency for the process. If assignments are clear and the follower performs well, a high-quality leader-member relationship should develop. However, if the assignments are clear and the follower does not perform, this will lead to a clearer process to document poor performance. It also gives leaders the chance to evaluate their own delegation to make sure they are clear in their expectations of employees. In all steps of the process, the follower can seek clarification from the leader so that both parties are clear regarding expectations.

Blockchain therefore encourages both leaders and direct reports to do as they say and say as they do. Leaders must be clear in what they assign and therefore expect of their employees. Employees on the other hand are required to clearly follow directions and report their efforts clearly as well. It requires self-awareness and provides an opportunity for self-assessment. For example, this might be well suited for transactional relationships, for individuals who are working distant from the local office, and for contract work. Also, in big firm type setting, lots of employees are required to $\log$ their hours for clients. This could be an additional step for leaders and employees to also provide specific details about what is expected from them and what they have completed.

\section{Performance Evaluations}

As discussed, performance evaluations are commonly used in organizations as a way to track employees' work and motivate them to continue to improve their skills. Currently, there are many different forms of performance evaluations and different organizations use different types of evaluation systems. Additionally, once leaving one workplace and moving to another one, performance is not consistently recorded. Blockchain can streamline this process and create more uniform agreed-upon protocols for evaluation. It also affords transparency to process (White, 2017). With blockchain, employees could keep a record of their performance as they move from one organization to another. This would provide a significant advantage to those individuals who are 
in fact performing consistently well. Blockchain, therefore, provides reliability for the performance evaluation process.

A possible drawback on using blockchain in all three areas above is organizational manipulation. Because some of the inputs into the blocks are vertically created, it is possible that incorrect information enters into the blocks. Due to immutability of blocks, this can tarnish an employee's career and inhibit future prosperity. Here, AI can help. If the information inputted into the system is not consistent with other sources (inputs) on the employee, such as prior history of the employee, and the inputs of other employees, the blockchain can flag this piece of information as possibly untrustworthy. Organization vertical decision-making can be susceptible to manipulation but a combination of AI and blockchain can lower this risk.

\section{The Ethics of Blockchain in Performance Management}

Virtue ethicists would look for the possibility of elevating human dignity in performance management. Distributed and verified performance management involving a large group of employees creates transparency, accountability, and trust. Employees are entitled to have a better understanding of the processes by which leaders assess their performance. Blockchain provides a step in this direction and can help elevate employees' potential. The downside of this technology on human flourishing is when a negative performance evaluation becomes sticky on one's profile. This creates roadblocks for the upward mobility of certain individuals especially if the performance evaluation is unfair. However, the distributed feature of performance evaluation aims to minimize such risk for individuals.

Utilitarians would likely find the reliability and verification process helpful in the ethical analysis. One consequence of this new form of performance management would be that the organizations would have reliable information about employees' assignments and resulting performance on those assignments. Due to the checks and balances process that is required to verify the assignments and the resulting performance on those assignments, the performance management process would be reliable and also transparent. Without blockchain technology, more bias could be included in the evaluation of employees. Another consequence, however, would once again relate to privacy. Individual performance evaluations, once recorded on a block, would be immutable. If an individual receives a poor performance evaluation, or experiences a conflict with his/her manager, this would be permanently recorded. Employees may be concerned with the extent to which this information could be viewed by future employers or if they would have control over what they could submit with their future applications.

Deontologists focus on the duty of candor and accountability both of which are enhanced pursuant to use of blockchain in performance management. Individuals are evaluated based on specific assigned tasks that have been verified, and their performance is verified by a network of people in the organization. Therefore, there is accountability in the specificity of assignments given by leaders and also accountability in the standard of performance of employees. There is however a possibility of harm especially as to the issue of privacy concepts, as discussed above. However, the need for candor and verification may outweigh the privacy concerns especially since the information relates to work performance.

Contractarians would like to see that employees are treated equally with regard to performance evaluations. Therefore, they would deem the process ethical if everyone is subject to the same evaluation process. Since blockchain technology would make the performance management process automated and streamlined, contractarians would consider this ethical. The least fortunate's performance will be evaluated in the same way as other employees and subject to the same process of checks and balances. Blockchain technology will provide all employees with the opportunity to perform well and succeed in the organization.

\section{Exit-Offboarding}

Offboarding, an employee's exit from the organization, presents similar issues as onboarding, one's entry to the organization. Blockchain can streamline and create trust in offboarding activities such as verification and transfer of employee documentation including performance evaluations, works completed, and certificate earned. Offboarding is another area in which transparency collides with the issue of privacy as in entry (onboarding). During offboarding, it is also important to effectively manage the challenges associated with transitioning the work team. If blockchain is effectively integrated into performance management (as detailed above), the work team can more efficiently fill in the roles of the employees who have departed the organization. Moreover, offboarding can also present potential risks including legal risks to the organization. Transparent performance management which is recorded on blockchain as described above provides the organization as well as the employees with a traceable performance record. Consequently, the organization and employees gain a better understanding of their respective liabilities and rights associated with offboarding. This can therefore result in a more accurate assessment of the resulting risks and ideally more equitable and efficient resolution of disputes.

\section{Discussion}

Blockchain is a new form of technology that is increasingly utilized by many organizations. Much of the discussion in blockchain pertains to DeFi and crypto-economics (Chen \& 
Bellavitis, 2020; Treleaven et al., 2017). In this paper, a discussion of the relevance of blockchain and its ethical implications for people operations is presented. We call this area DePo in which the human experience in organizations will be most affected by blockchain and AI. This paper presents a discussion of the importance of blockchain for recruitment and selection, compensation via smart contracts, retention and motivation, and performance management. The paper also introduces ethical challenges and ethical views related to use of blockchain in human resource management. In sum, this paper offers a new theoretical framework for DePo which can help the transition from viewing humans as "resources" in the organization to decision-makers.

This paper contributes to the literature at the intersection of human resources and technology. Stone et al. (2015) reviewed the literature on human resources and technology and found that although research exists on the topic it is at a nascent stage. For example, research has started to examine e-recruitment factors that affect attraction to organizations, but has not assessed the effects on successful placements or retention rates (Dineen \& Allen, 2013; Dineen \& Soltis, 2011; Stone et al., 2003, 2005). Other research has begun to analyze whether e-recruitment affects the diversity of applicants and hires and found that e-recruiting may not actually help organizations increase workplace diversity (Kuhn \& Skuterud, 2000; McManus \& Ferguson, 2003; Zusman $\&$ Landis, 2002). Stone et al. (2015) called for additional research to examine the extent to which the implementation of technology in human resource practices enables organizations to achieve their human resource goals. Our research thus contributes to this emerging area at the intersection of human resources and technology by focusing on its capabilities along with the associated ethical ramifications. We provide specific tangible recommendations as to the ways in which blockchain technology can enable organizations to improve their human resource practices.

Further, we contribute to the burgeoning literature on ethics and human resources. A special issue in the Journal of Business Ethics set out to restart ethical inquiries of the theory and practice of human resources (Jack et al., 2012). Central to conversations in this area are ethical tensions about the commodification of labor, potential threats to human rights and personal liberty, the virtue, autonomy and moral well-being of employees and managers among other topics (Jack et al, 2012). Following Greenwood's (2013) recommendations for research at the intersection of ethics and human resources, our paper contributes to this literature by examining and integrating multiple ethical theories simultaneously offering varying perspectives to the issues at hand. Similarly, we provide a normative perspective and one that considers the overall organizational context in which the issues exist. With this, we consider a stakeholder model in which the emphasis is on engaging in shared leadership and collective participation in different aspects of people operations.

The primary goal of this paper was to provide a first glimpse into the ways in which blockchain technology can be used in enhancing current micro-organizational practices along with its ethical ramifications. Organizations can expand the use of blockchain to their people operations including human resources and leadership. Additionally, organizations that are new to blockchain can start using blockchain in their people operations practices. Blockchain provides transparency, accountability and trust to commonly used human resource practices while also saving time and costs. It is important to also be cognizant of the ethical issues that are novel to the implementation of blockchain in human resource practices.

Examining the virtue ethics, utilitarian, deontology, and contractarian perspectives, we suggest that blockchain technology provides opportunities for organizations to improve their human resources practices to be more efficient and also more ethical. Blockchain allows prospective employees to be transparent in their applications avoiding deception, gives them clear expectations when working in the organization, and provides them with outlets to increase their voice behaviors and participate in organizational decisions. Blockchain also provides the tools organizations need to create a more just workplace, be straightforward in their expectations of employees, and allows for the creation of smart contracts for compensation and conflict resolution. All in all, these efforts create a more ethical work environment.

Particularly, we believe that at the entry and offboarding states, contractarianism provides a suitable roadmap to determine the ethical nature of the tensions between privacy and transparency. Organizations desire to have reliable and transparent information about its applicants. On the other hand, individuals' desire to have control over their information. A contractarian would investigate a hypothetical social contract and determine that transparency may outweigh the privacy concern. Moreover, privacy concerns may be alleviated by giving more control to individuals over the type of information that blockchain will record immutably.

As to the financial aspect, individuals and organizations would both benefit from having a predetermined objective criterion for compensation. Utilitarianism can help the most here by focusing on the consequences to evaluate its ethical aspects. The main ethical aspect of using smart contracts in the financial aspect pertains to the lack of flexibility of such contracts which makes ex post adjustment difficult. An effective distributed dispute resolution process can alleviate this concern.

Horizontal decision-making in organizations aims to foster retention and motivation. The use of blockchain can create more equal opportunity for all employees through the concept of shared leadership, supporting the contractarian 
Table 1 Blockchain applications, ethical issues, and suggested ethical perspectives in people operations

\begin{tabular}{|c|c|c|c|c|}
\hline & & Blockchain applications & Major ethical issues & Suggested ethical perspective \\
\hline Entry & Recruitment and selection & $\begin{array}{l}\text { Verify applicant documentation } \\
\text { including: } \\
\text { Degrees } \\
\text { Micro-credentials } \\
\text { Performance evaluations } \\
\text { References } \\
\text { Employment certificate } \\
\text { Awards }\end{array}$ & $\begin{array}{l}\text { Transparency } \\
\text { Privacy } \\
\text { Stickiness of the records }\end{array}$ & $\begin{array}{l}\text { Contractarianism-focusing on ex- } \\
\text { ante expectations of individuals } \\
\text { regardless of status }\end{array}$ \\
\hline \multirow[t]{3}{*}{ Internal } & $\begin{array}{l}\text { Financial: } \\
\text { Compensation }\end{array}$ & $\begin{array}{l}\text { Smart contract immediate } \\
\text { payment upon completion of } \\
\text { assigned time period or task }\end{array}$ & $\begin{array}{l}\text { Automation } \\
\text { Minimization of breach } \\
\text { Lack of entry points } \\
\text { Lack of negotiation or bargaining }\end{array}$ & $\begin{array}{l}\text { Utilitarianism-focusing on utility } \\
\text { of smart contracts in streamlining } \\
\text { compensation }\end{array}$ \\
\hline & $\begin{array}{l}\text { Horizontal: } \\
\text { Retention and Motivation }\end{array}$ & $\begin{array}{l}\text { Shared leadership and decision- } \\
\text { making } \\
\text { Conflict resolution via smart } \\
\text { smarts and consensus mecha- } \\
\text { nisms }\end{array}$ & $\begin{array}{l}\text { Giving voice } \\
\text { Accountability } \\
\text { Possibility of collusion } \\
\text { Possibility of bias }\end{array}$ & $\begin{array}{l}\text { Virtue Ethics_-focusing on } \\
\text { employees flourishing in a shared } \\
\text { leadership environment }\end{array}$ \\
\hline & $\frac{\text { Vertical: }}{\text { Performance Management }}$ & $\begin{array}{l}\text { Background verification prior to } \\
\text { team and leader assignment } \\
\text { Assignment verification } \\
\text { Performance evaluation based on } \\
\text { consensus mechanism }\end{array}$ & $\begin{array}{l}\text { Candor } \\
\text { Accountability } \\
\text { Organizational manipulation }\end{array}$ & $\begin{array}{l}\text { Deontology_-focusing on the duty } \\
\text { of candor in providing perfor- } \\
\text { mance evaluations }\end{array}$ \\
\hline Exit & Offboarding & $\begin{array}{l}\text { Verify employee documentation } \\
\text { including: } \\
\text { Performance evaluations } \\
\text { Work completed (i.e. projects, } \\
\text { subject matter) } \\
\text { Work certificates earned } \\
\text { Tenure in organization/ Hours } \\
\text { worked }\end{array}$ & $\begin{array}{l}\text { Transparency } \\
\text { Privacy } \\
\text { Stickiness of the records }\end{array}$ & $\begin{array}{l}\text { Contractarianism-focusing on ex- } \\
\text { ante expectations of individuals } \\
\text { regardless of status }\end{array}$ \\
\hline
\end{tabular}

ethical viewpoint. Shared leadership may result in delays in decision-making but a robust underlying incentive structure (something akin to the Bitcoin incentive mechanism) can create more expeditious decision-making by a large group of employees. The vertical decision-making approach pertains to performance management. Blockchain can create more candor and truthfulness as deemed important by virtue ethicists through assignment verification and consensusbased evaluation. There is a danger of false information and organizational manipulation. However, as explained above, AI can help find anomalies in inputs given past performance and other employee reports and flag the erroneous information on the block.

In sum, the use of blockchain in people operations raises substantial ethical issues which have not been thoroughly investigated. Table 1 summarizes blockchain applications, associated major ethical issues, and suggested ethical perspectives in all three phases of people operations:

\section{Future Directions for Research}

Each of the propositions presented in the paper can be expanded into several research studies that explore the implications of blockchain. We recommend that future research test the propositions put forth in this paper with empirical studies. Examinations of ethical perceptions of the use of blockchain for people operations and other microorganizational issues can be a fruitful future line of inquiry. Field studies in which blockchain technology is implemented into daily human resource management and leadership practices will best be able to access the benefits and concerns with the technology. However, empirical research can also test the hypothetical impact of blockchain technology in weeks-long simulated experiences in which transactions are recorded on blocks and then verified by other participants. Moreover, AI adds another level to the complexity of ethical issues associated with the blockchain discussion. This is because AI can also feed information into blockchain that is from outside the organization. This can be explored in depth in future research.

Additionally, further research is needed to examine ethical issues arising from blockchain at the macro-level. The use of blockchain in business has broad implications for society and the global economy. For example, through disintermediation, blockchain may result in significant job loss within conventional sectors of the economy. It may lead to a 
dramatic restructuring of those sectors. Many also anticipate a shift in earning capacity (i.e. changes in sweat equity and income). These issues deserve much attention in the business ethics literature.

\section{Practical Implications}

Given the transparency required with blockchain, this leads to organizations that extremely value authentic leadership and followership. Authentic leadership and followership require individuals to have self-awareness, an internalized moral perspective, a balanced processing of information and relational transparency (Walumbwa et al., 2008). With blockchain, it makes it more straightforward for individuals to act in an authentic way. This is because leaders and followers are expected to be authentic in order for the system to work. The system of checks and balances also requires that all followers be authentic as well. As described above, the requirement for information to be recorded and verified on blocks, allows only true and reliable information to exist in the workflow of organizational relationships.

Years of research has shown the benefits of authentic leadership including employee task performance, organizational citizenship behaviors, voice, job satisfaction, organizational commitment, creativity, engagement and empowerment (Banks et al., 2016). The more that an organization can encourage such authentic behavior, the more long-term benefits they can expect to see with their employees. Implementation of blockchain in the organization is therefore an organizational strategy that can have an effect on leader and employee behavior.

Organizations that employ practices that encourage transparency and authenticity are also seeding organizational cultures that are based on trust and ethics. With blockchain technology, organizations make it easier for leaders and employees to be transparent in their expectations and performance output. Research on leader-member exchange has indicated that trust is one of the major components of highquality relationships (Graen \& Uhl-Bien, 1995). Blockchain technology therefore has the potential to encourage a culture of trust in the organization.

Further, organizations with strong positive organizational cultures also have positive relationships with their customers (Rahimi, 2017). A culture of authenticity and trust should also trickle down to relationships with clients and customers. When employees show that they care about the services that they are providing, customers typically feel this effort. This will lead to long-term authentic relationships with customers.

However, the implementation of blockchain within organizations should be carefully thought out to avoid significant employee dissent. Careful implementation, like any other change initiative, will help retain employee trust. Long-term benefits associated with the implementation of blockchain technology should be well communicated by the organization and its leaders at all levels. Employees' reactions to the use of their data might have negative consequences for organizations. Research has indicated the importance of the trust with regard to blockchain technology (Dierksmeier \& Seele, 2018; Whelan, 2019) and resulting organizational reputation (Carroll \& Olegario, 2020). If employees feel as though their privacy is being violated, they might feel that the organization is unethical and therefore lose trust, be less committed and be less motivated at work.

\section{Conclusion}

This research provides us with a preview into the possibilities of the implementation of blockchain technology into people operations processes at organizations at entry, in intraorganizational affairs and during outboarding. Ethical implications are discussed in detail from the viewpoints of virtue ethics, utilitarianism, deontology and contractarianism. We conclude that in whole the implementation of blockchain technology in people operations processes can create a more ethical work environment. However, careful implementation is necessary and requires extensive examination of ethical implications in advance. The goal of this work is to spur further research on the implications of blockchain in people operations processes in the field of ethics and to encourage organizational implementation of the technology.

\section{Declarations}

Conflict of interest There are no conflicts of interests associated with this paper. This research does not have data and therefore does not involve human participants nor does it require informed consent.

\section{References}

Ackerman, B. (1997). Temporal horizons of justice. The Journal of Philosophy, 94(6), 299-317.

Aitzhan, N. Z., \& Svetinovic, D. (2016). Security and privacy in decentralized energy trading through multi-signatures, blockchain and anonymous messaging streams. IEEE Transactions on Dependable and Secure Computing, 15(5), 840-852.

Akter, S., Michael, K., Uddin, M. R., McCarthy, G., \& Rahman, M. (2020). Transforming business using digital innovations: The application of AI, blockchain, cloud and data analytics. Annals of Operations Research. https://doi.org/10.1007/ s10479-020-03620-w

Alkhudary, R., Brusset, X., \& Fenies, P. (2020). Blockchain in general management and economics: A systematic literature review. European Business Review. https://doi.org/10.1108/ EBR-11-2019-0297 
Allen, D. G., Bryant, P. C., \& Vardaman, J. M. (2010). Retaining talent: Replacing misconceptions with evidence-based strategies. Academy of Management Perspectives, 24(2), 48-64.

Angel, J. J., \& McCabe, D. (2015). The ethics of payments: Paper, plastic, or Bitcoin? Journal of Business Ethics, 132(3), 603-611.

Annas, J. (2004). Being virtuous and doing the right thing. Proceedings and Addresses of the American Philosophical Association, 78(2), 61-75.

Aquino, K., Griffeth, R. W., Allen, D. G., \& Hom, P. W. (1997). Integrating justice constructs into the turnover process: A test of a referent cognitions model. Academy of Management Journal, 40(5), 1208-1227.

Ashkenas, R. (1995). The boundaryless organization: Breaking the chains of organizational structure. The Jossey-Bass Management Series.

Banks, G. C., McCauley, K. D., Gardner, W. L., \& Guler, C. E. (2016). A meta-analytic review of authentic and transformational leadership: A test for redundancy. The Leadership Quarterly, 27(4), 634-652.

BasuMallick, C. (2020). 10 Startups using blockchain to answer key HR, HR technologist. https://www.hrtechnologist.com/articles/ digital-transformation/top-blockchain-hr-startups/

Bertland, A. (2009). Virtue ethics in business and the capabilities approach. Journal of Business Ethics, 84(1), 25-32.

Böhme, R., Christin, N., Edelman, B., \& Moore, T. (2015). Bitcoin: Economics, technology, and governance. Journal of Economic Perspectives, 29(2), 213-238.

Brady, F. N., \& Dunn, C. P. (1995). Business meta-ethics: An analysis of two theories. Business Ethics Quarterly, 5(3), 385-398.

Brewer, K. B. (1997). Management as a practice: A response to Alasdair MacIntyre. Journal of Business Ethics, 16(8), 825-833.

Brinsfield, J. W. (1998). Army values and ethics: A search for consistency and relevance. The US Army War College Quarterly: Parameters, 28(3), 5 .

Card, C. (2010). The unnatural lottery: Character and moral luck. Temple University Press.

Carroll, C. E., \& Einwiller, S. A. (2014). Disclosure alignment and transparency signaling in CSR reports. In Communication and language analysis in the corporate world (pp. 249-270). IGI Global.

Carroll, C. E., \& Olegario, R. (2020). Pathways to corporate accountability: Corporate reputation and its alternatives. Journal of Business Ethics. https://doi.org/10.1007/s10551-021-05020-x

Casey, M. J., \& Vigna, P. (2018). In blockchain we trust. MIT Technology Review, 121(3), 10-16.

Casino, F., Politou, E., Alepis, E., \& Patsakis, C. (2019). Immutability and decentralized storage: An analysis of emerging threats. IEEE Access, 8, 4737-4744.

del Castillo, M. (2019). Blockchain goes to work at Walmart, Amazon, JPMorgan, Cargill and 46 other enterprises. Forbes. Retrieved from https://www.forbes.com/sites/michaeldelcastillo/2019/04/ 16/blockchain-goes-to-work/\#32ee12ef2a40

Chang, S. E., \& Chen, Y. (2020). When blockchain meets supply chain: A systematic literature review on current development and potential applications. IEEE Access, 8, 62478-62494

Chen, Y., Chen, S., \& Lin, I. (2018). Blockchain based smart contract for bidding system. Paper presented at the 2018 IEEE international conference on applied system invention (ICASI) (pp. 208-211).

Chen, Y., \& Bellavitis, C. (2020). Blockchain disruption and decentralized finance: The rise of decentralized business models. Journal of Business Venturing Insights, 13, e00151.

Chowdhury, M. J. M., Colman, A., Kabir, M. A., Han, J., \& Sarda, P. (2018). Blockchain versus database: A critical analysis. In 2018 17th IEEE International conference on trust, security and privacy in computing and communications/12th IEEE international conference on big data science and engineering (TrustCom/BigDataSE) (pp. 1348-1353). IEEE.

Cody, W. M., \& Lynn, R. R. (1992). Honest government: An ethics guide for public service. ABC-CLIO.

Colquitt, J. A., Conlon, D. E., Wesson, M. J., Porter, C. O., \& Ng, K. Y. (2001). Justice at the millennium: A meta-analytic review of 25 years of organizational justice research. Journal of Applied Psychology, 86(3), 425.

McKinsey \& Company. (2020). How covid-19 has pushed companies over the technology tipping point and transformed business forever. https://www.mckinsey.com/business-functions/strat egy-and-corporate-finance/our-insights/how-covid-19-haspushed-companies-over-the-technology-tipping-point-andtransformed-business-forever

Corkery, M., \& Popper, N. (2018). From farm to blockchain: Walmart tracks its lettuce. New York Times. Retrieved from https://www.nytimes.com/2018/09/24/business/walmart-block chain-lettuce.html

Dean, P. J. (1992). Making codes of ethics 'real.' Journal of Business Ethics, 11(4), 285-290.

Devanna, M. A., \& Tichy, N. (1990). Creating the competitive organization of the 21 st century: The boundaryless corporation. Human Resource Management, 29(4), 455-471.

Dierksmeier, C., \& Seele, P. (2018). Cryptocurrencies and business ethics. Journal of Business Ethics, 152(1), 1-14.

Dierksmeier, C., \& Seele, P. (2020). Blockchain and business ethics. Business Ethics: A European Review, 29(2), 348-359.

Dineen, B. R., \& Allen, D. G. (2013). Internet recruiting 2.0: shifting paradigms. In K. Y. T. Yu, \& D. M. Cable (Eds.), The Oxford handbook of recruitment (pp. 382-401). New York: Oxford University Publishers.

Dineen, B. R., \& Soltis, S. M. (2011). Recruitment: A review of research and emerging directions. In S. Zedeck (Ed.), APA handbook of industrial and organizational psychology (Vol. 2, pp. 43-66). American Psychological Association.

Dunfee, T. W., \& Donaldson, T. (1995). Contractarian business ethics: Current status and next steps. Business Ethics Quarterly, 5(2), 173-186.

Fachrunnisa, O., \& Hussain, F. K. (2020). Blockchain-based human resource management practices for mitigating skills and competencies gap in workforce. International Journal of Engineering Business Management. https://doi.org/10.1177/18479 79020966400

Farrar, L. (2019). Human Resources 2.0: How people operations is powering higher productivity. Forbes. https://www.forbes. com/sites/laurelfarrer/2019/03/28/human-resources-2-0-howpeople-operations-is-powering-higher-productivity/?sh $=3494 \mathrm{e}$ $0 \mathrm{~b} 64 \mathrm{~b} 4 \mathrm{~b}$

Felin, T., \& Lakhani, K. (2018). What problems will you solve with blockchain? MIT Sloan Management Review, 60(1), 32-38.

De Filippi, P. (2015). Translating commons-based peer production into metrics: Towards commons-based crypto-currencies. In D. Lee \& K. Chuen (Ed.), The handbook of digital currency. Amsterdam: Elsevier.

De Filippi, P., \& Loveluck, B. (2016). The invisible politics of Bitcoin: Governance crisis of a decentralised infrastructure. Internet Policy Review. https://doi.org/10.14763/2016.3.427.

Foot, P. (2003). Natural goodness. Clarendon Press.

Frenken, K., Vaskelainen, T., Fünfschilling, L., \& Piscicelli, L. (2020). An institutional logics perspective on the gig economy. Variety and trajectories of new forms of organizing. Emerald Publishing Limited.

Frizzo-Barker, J., Chow-White, P. A., Adams, P. R., Mentanko, J., Ha, D., \& Green, S. (2020). Blockchain as a disruptive technology for business: A systematic review. International Journal of Information Management, 51, 102029. 
Gajendran, R. S., \& Joshi, A. (2012). Innovation in globally distributed teams: The role of LMX, communication frequency, and member influence on team decisions. Journal of Applied Psychology, 97(6), 1252.

Ghodoosi, F. (2021). Contracting in the age of smart contracts. Washington Law Review, https://ssrn.com/abstract $=3449674$.

Ghodoosi, F., \& Sharif, M. M. (2021). Justice in arbitration: The consumer perspective. International Journal of Conflict Management, 32(4), 626-647.

Gier, N. F. (2001). The dancing Ru: A Confucian aesthetics of virtue. Philosophy East and West, 51(2), 280-305.

Graen, G. B., \& Scandura, T. A. (1987). Toward a psychology of dyadic organizing. Research in Organizational Behavior, 9, 175-208.

Graen, G. B., \& Uhl-Bien, M. (1995). Relationship-based approach to leadership: Development of leader-member exchange (LMX) theory of leadership over 25 years: Applying a multi-level multidomain perspective. The Leadership Quarterly, 6(2), 219-247.

Greenwood, M. R. (2002). Ethics and HRM: A review and conceptual analysis. Journal of Business Ethics, 36(3), 261-278.

Greenwood, M. (2013). Ethical analyses of HRM: A review and research agenda. Journal of Business Ethics, 114(2), 355-366.

Gudkov, A. (2020). Crowd arbitration: Blockchain dispute resolution. Legal Issues in the Digital Age. https://digitalawjournal.hse.ru/ article/view/11780.

Hansen, R. S. (1992). A multidimensional scale for measuring business ethics: A purification and refinement. Journal of Business Ethics, 11(7), 523-534.

He, S. (2020). Impact of blockchain applications on trust in business. iBusiness, 12(3), 103-112.

Hofmann, F., Wurster, S., Ron, E., \& Böhmecke-Schwafert, M. (2017). The immutability concept of blockchains and benefits of early standardization. In 2017 ITU Kaleidoscope: Challenges for a data-driven society (ITU K) (pp. 1-8). IEEE.

Hunt, S. D., \& Vasquez-Parraga, A. Z. (1993). Organizational consequences, marketing ethics, and salesforce supervision. Journal of Marketing Research, 30(1), 78-90.

Hyrynsalmi, S., Hyrynsalmi, S. M., \& Kimppa, K. K. (2020). Blockchain ethics: A systematic literature review of blockchain research. In International conference on well-being in the information society (pp. 145-155). Springer.

Iansiti, M., \& Lakhani, K. R. (2017). The truth about blockchain. Harvard Business Review, 95(1), 118-127.

Work Institute. (2019). 2019 Retention Report. http://workinstitute. com/retentionreport2019.

Jack, G., Greenwood, M., \& Schapper, J. (2012). Frontiers, intersections and engagements of ethics and HRM. Journal of Business Ethics, 111(1), 1-12.

Kher, R., Terjesen, S., \& Liu, C. (2020). Blockchain, bitcoin, and ICOs: A review and research agenda. Small Business Economics, 56(2), $1-22$.

Kimani, D., Adams, K., Attah-Boakye, R., Ullah, S., Frecknall-Hughes, J., \& Kim, J. (2020). Blockchain, business and the fourth industrial revolution: Whence, whither, wherefore and how? Technological Forecasting and Social Change, 161, 120254.

Klarin, A. (2020). The decade-long cryptocurrencies and the blockchain rollercoaster: Mapping the intellectual structure and charting future directions. Research in International Business and Finance, 51, 101067.

Koehn, D. (1995). A role for virtue ethics in the analysis of business practice. Business Ethics Quarterly, 5, 533-539.

Kuhn, P., \& Skuterud, M. (2000). Job search methods: Internet versus traditional. Monthly Labor Review, 123, 3-11.

Limbs, E. C., \& Fort, T. L. (2000). Nigerian business practices and their interface with virtue ethics. Journal of Business Ethics, 26(2), 169-179.
Louden, R. B. (1992). Morality and moral theory: A reappraisal and reaffirmation. Oxford University Press on Demand.

Markovits, D. (2004). The No-Retraction Principle and the Morality of Negotiations. University of Pennsylvania Law Review, 152(6), 1903-1921.

McCracken, J., Martin, W., \& Shaw, B. (1998). Virtue Ethics and the Parable of the Sadhu. Journal of Business Ethics, 17(1), 25-38.

McManus, M. A., \& Ferguson, M. W. (2003). Biodata, personality, and demographic differences of recruits from threes sources. International Journal of Selection and Assessment, 11, 175-183.

Metzger, J. (2018). Decentralized Justice in the Era of Blockchain. IJODR, 5, 69.

Meyer, C., \& Hudon, M. (2019). Money and the commons: An investigation of complementary currencies and their ethical implications. Journal of Business Ethics, 160(1), 277-292.

Meyer, J. P., \& Allen, N. J. (1991). A three-component conceptualization of organizational commitment. Human Resource Management Review, 1(1), 61-89.

Micewski, E. R., \& Troy, C. (2007). Business ethics-deontologically revisited. Journal of Business Ethics, 72(1), 17-25.

Murphy, P. E. (1999). Character and virtue ethics in international marketing: An agenda for managers, researchers and educators. Journal of Business Ethics, 18(1), 107-124.

Natarajan, H., Krause, S., \& Gradstein, H. (2017). Distributed ledger technology and blockchain. World Bank.

Nussbaum, M. (2000). Women's capabilities and social justice. Journal of Human Development, 1(2), 219-247.

Nussbaum, M. C. (2011). Capabilities, entitlements, rights: Supplementation and critique. Journal of Human Development and Capabilities, 12(1), 23-37.

Öncu, K. (2019). Software development methodology selection with human resource management approach and a new system design on database: Blockchain application. Quantrade Journal of Complex Systems in Social Sciences, 1(1), 28-39.

Orlikowski, W. J. (2000). Using technology and constituting structures: A practice lens for studying technology in organizations. Organization Science, 11(4), 404-428.

Pearce, C. L., \& Conger, J. A. (2002). Shared leadership: Reframing the hows and whys of leadership. Sage.

Pearce, C. L., Conger, J. A., \& Locke, E. A. (2008). Shared leadership theory. The Leadership Quarterly, 19(5), 622-628.

Pierson, E., Corbett-Davies, S., \& Goel, S. (2018). Fast threshold tests for detecting discrimination. In International conference on artificial intelligence and statistics (pp. 96-105).

Quiniou, M. (2019). Blockchain: The advent of disintermediation. Wiley.

Radin, M. J. (2012). Boilerplate: The fine print, vanishing rights, and the rule of law. Princeton University Press.

Rahimi, R. (2017). Organizational culture and customer relationship management: A simple linear regression analysis. Journal of Hospitality Marketing \& Management, 26(4), 443-449.

Rawlins, B. (2008). Give the emperor a mirror: Toward developing a stakeholder measurement of organizational transparency. Journal of Public Relations Research, 21(1), 71-99.

Rawls, J. (1991). Justice as fairness: Political not metaphysical. In Equality and liberty (pp. 145-173). Palgrave Macmillan.

Rees, C., Alfes, K., \& Gatenby, M. (2013). Employee voice and engagement: Connections and consequences. The International Journal of Human Resource Management, 24(14), 2780-2798.

Rim, H., Swenson, R., \& Anderson, B. (2019). What happens when brands tell the truth? Exploring the effects of transparency signaling on corporate reputation for agribusiness. Journal of Applied Communication Research, 47(4), 439-459.

Sandner, P. (2021). Decentralized finance will change your understanding of financial systems. Forbes. https://www.forbes. com/sites/philippsandner/2021/02/22/decentralized-finan 
ce-will-change-your-understanding-of-financial-systems/?sh= $7 \mathrm{c} 0 \mathrm{bfd} 825 \mathrm{~b} 52$

Sarda, P., Chowdhury, M. J. M., Colman, A., Kabir, M. A., \& Han, J. (2018). Blockchain for fraud prevention: a work-history fraud prevention system. In: 2018 17th IEEE international conference on trust, security and privacy in computing and communications/12th IEEE international conference on big data science and engineering (TrustCom/BigDataSE) (pp. 1858-1863). IEEE.

Scheffler, S. (2002). Boundaries and allegiances: Problems of justice and responsibility in liberal thought. Oxford University Press on Demand.

Schmitz, A., \& Rule, C. (2019). Online dispute resolution for smart contracts. Journal of Dispute Resolution. https://scholarship.law. missouri.edu/facpubs/726

Seeger, M. W., \& Ulmer, R. R. (2001). Virtuous responses to organizational crisis: Aaron Feuerstein and Milt Colt. Journal of Business Ethics, 31(4), 369-376.

Seidel, M. D. L. (2018). Questioning centralized organizations in a time of distributed trust. Journal of Management Inquiry, 27(1), 40-44.

Shanahan, K. J., \& Hyman, M. R. (2003). The development of a virtue ethics scale. Journal of Business Ethics, 42(2), 197-208.

Solomon, R. C. (1992). Ethics and excellence: Cooperation and integrity in business. Oxford University Press.

Spencer, D. G. (1986). Employee voice and employee retention. Academy of Management Journal, 29(3), 488-502.

Stone, D. L., Deadrick, D. L., Lukaszewski, K. M., \& Johnson, R. (2015). The influence of technology on the future of human resource management. Human Resource Management Review, 25(2), 216-231.

Stone, D. L., Lukaszewski, K., \& Isenhour, L. C. (2005). E-Recruiting: Online strategies for attracting talent. In H. G. Gueutal \& D. L. Stone (Eds.), The brave new world of eHR: Human resources management in the digital age (pp. 22-53). Jossey Bass.

Stone, D. L., Stone-Romero, E. F., \& Lukaszewski, K. (2003). The functional and dysfunctional consequences of human resource information technology for organizations and their employees. In D. Stone (Ed.), Advances in human performance and cognitive engineering research (Vol. 3, pp. 37-68). Elsevier.

Sulkowski, A. J. (2020). The Tao of DAO: Hardcoding business ethics on blockchain. The Business \& Finance Law Review, 3, 146.
Szabo, N. (1996). Smart contracts: Building blocks for digital markets. EXTROPY: the Journal of Transhumanist Thought, 16(2), 18.

Tang, Y., Xiong, J., Becerril-Arreola, R., \& Iyer, L. (2020). Ethics of blockchain. Information Technology \& People, 33(2), 602-632.

Tapscott, D., \& Tapscott, A. (2017). How blockchain will change organizations. MIT Sloan Management Review, 58(2), 10.

Tessman, L. (2000). Moral luck in the politics of personal transformation. Social Theory and Practice, 26(3), 375-395.

Treleaven, P., Brown, R. G., \& Yang, D. (2017). Blockchain technology in finance. Computer, 50(9), 14-17.

Truong, N. B., Um, T., Zhou, B., \& Lee, G. M. (2018). Strengthening the blockchain-based internet of value with trust. Paper presented at the 2018 IEEE international conference on communications (ICC) (pp. 1-7).

Tsui, A. S., Nifadkar, S. S., \& Ou, A. Y. (2007). Cross-national, crosscultural organizational behavior research: Advances, gaps, and recommendations. Journal of Management, 33(3), 426-478.

Walumbwa, F. O., Avolio, B. J., Gardner, W. L., Wernsing, T. S., \& Peterson, S. J. (2008). Authentic leadership: Development and validation of a theory-based measure. Journal of Management, 34(1), 89-126.

Wang, S., Ding, W., Li, J., Yuan, Y., Ouyang, L., \& Wang, F. Y. (2019). Decentralized autonomous organizations: Concept, model, and applications. IEEE Transactions on Computational Social Systems, 6(5), 870-878.

Werbach, K. (2018). The blockchain and the new architecture of trust. MIT.

Whelan, G. (2019). Trust in surveillance: A reply to Etzioni. Journal of Business Ethics, 156(1), 15-19.

White, G. R. (2017). Future applications of blockchain in business and management: A Delphi study. Strategic Change, 26(5), 439-451.

Xu, M., Chen, X., \& Kou, G. (2019). A systematic review of blockchain. Financial Innovation, 5(1), 1-14.

Zusman, R. R., \& Landis, R. S. (2002). Applicant preferences for web-based versus traditional job postings. Computer in Human Behavior, 18, 285-296.

Publisher's Note Springer Nature remains neutral with regard to jurisdictional claims in published maps and institutional affiliations. 